\title{
Filipińskie kino w odcieniach różu
}

\author{
MARIA DELIMATA
}

Współczesne kino filipińskie bynajmniej nie jest dobrze znane i promowane w Polsce, choć na tle kinematografii Azji Południowo-Wschodniej zdecydowanie wyróżnia się oryginalnością i odwagą w mówieniu o problemach społecznych i politycznych. Można wskazać jedynie kilka filmów, które w ciągu ostatnich lat pojawiły się na wybranych, często niezależnych, festiwalach i w nielicznych polskich kinach. W Europie - m.in. na festiwalu w Cannes - uznanie zdobył już Brillante Mendoza, reżyser należący do tak zwanego nowego kina filipińskiego - za takie filmy, jak Kinatay (dość niefortunnie tłumaczony z języka tagalog jako Masakra), Lola (Babcia) czy Captive (Pozdrowienia $z$ raju). Wszystkie te filmy, które choć na chwilę zaistniały w świadomości polskich kinomanów, łączy przede wszystkim bezwzględność i odwaga w pokazywaniu brutalnej, wręcz przerażającej rzeczywistości Filipin i samej Manili - często nazywanej najmroczniejszą stolicą świata.

Odmiennie rysują się na tym tle filmy, których głównym tematem jest kwestia tożsamości

[1] Choć jest to bez wątpienia określenie najpopularniejsze, warto zwrócić uwagę, iż bakla wywodzi się z języka tagalog (drugiego, obok angielskiego, języka urzędowego, którym mówi znacząca część populacji wyspy Luzon). $\mathrm{Na}$ Filipinach można się jednak spotkać z szeregiem innych określeń - w zależności od użycia lokalnych języków i przynależności do mniejszości etnicznej.

[2] Por. „For instance, in the case of the bakla, a qualitative difference from Western homosexuality may be the rather strange preponderance of 'straight-gay' relationships in the local culture, unheard of and incomprehensible to the dualistic, Western mind". J.N.C. Garcia, Philippine Gay Culture, wyd. 2, University of the Philippines Press, Quezon City 2008, s. 250. seksualnej/genderowej - jak Maximo Oliveros rozkwita (Ang Pagdadalaga ni Maximo Oliveros), debiut reżyserski Auraeusa Solito, prezentowany na XXII Warszawskim Międzynarodowym Festiwalu Filmowym, czy, zupełnie nieznany w Polsce, Zsazsa Zaturnnah: Ze Moveeh Joela C. Lamangana. To właśnie te dwa tytuły staną się głównym tematem niniejszego artykułu.

Choć oba filmy więcej dzieli, niż łączy, nie sposób nie dostrzec istniejącej pomiędzy nimi paraleli - obaj tytułowi bohaterowie są ba$k l a[1]$ - filipińskimi gejami. Tłumaczenie tego słowa przy użyciu pojęć wypracowanych w tak zwanej kulturze Zachodu (a przede wszystkim przy zastosowaniu tradycyjnie rozumianej opozycji: homoseksualność vs. heteroseksualność) powoduje jednak szereg problemów. Wyraz bakla bowiem może oznaczać zarówno "geja” homoseksualistę nawiązującego relację z innym homoseksualistą (wtedy jednak jest najczęściej używany w znaczeniu obraźliwym), jak i sfeminizowanego mężczyznę, performującego swoją płciowość i tożsamość - przybierającego żeńskie imię, „upodabniającego się" wyglądem do kobiety, zainteresowanego relacją z heteroseksualnym mężczyzną[2].

Nie bez przyczyny to właśnie określenie "performować” wydaje się w tym kontekście najbardziej adekwatne do rzeczywistości. Choć granica między odgrywaniem, wchodzeniem w rolę a „stawaniem się" daną osobą może być postrzegana jako niezwykle płynna, w opisywanym kontekście mamy do czynienia z zupełnie odmienną strategią. Elementy teatralności mogą być, rzecz jasna, dostrzegane w takich praktykach, jak cross-dressing (a zatem zakładanie stroju konwencjonalnie - a jednocześnie w porządku heteronormatywnym - przynależnego do przedstawicieli innej płci seksualnej), bakla jednak nie tyle temporalnie odgrywa by- 
cie kobietą (jak czynią to na przykład transwestyci), ile usilnie stara się w nią przeistoczyć. Nie można jednak mylić tego zjawiska $\mathrm{z}$ transseksualizmem - wszak zmiana płci prawie nigdy nie wchodzi tu w grę: bakla fizycznie pozostaje mężczyzną, nigdy nie przejdzie operacji zmiany płci; sam siebie uznaje jednak za kobietę[3]. Z tego też względu w próbach naukowego opisu tego fenomenu celniejsze wydaje się posługiwanie teorią performatywną: bakla performuje swoją płciowość, a dzięki temu procesowi (re)konstruuje i buduje własną tożsamość.

Bakla to przede wszystkim trzecia, osobna płeć. Jak wskazał Neil C. Garcia, jeden z najważniejszych filipińskich naukowców zajmujących się problematyką gender i queer studies - w powszechnej świadomości jest także „trzecia” w hierarchicznej kolejności: po lalake (mężczyźnie) i babae (kobiecie), jednak przed tomboy (lesbijką-butchem) [4].

Trudno arbitralnie określić, na ile homoseksualizm jest akceptowany przez społeczeństwo filipińskie. Trzeba bowiem pamiętać o skomplikowanej historii tego kraju, po części - jak chcieliby widzieć niektórzy - azjatyckiego, jednak napiętnowanego historią kolonizacji, najpierw kilkusetletniej hiszpańskiej, a następnie dwudziestowiecznej amerykańskiej. Wpływ katolicyzmu - widzianego również przez pryzmat postkolonialny - jeszcze bardziej utrudnia jednoznaczną ocenę dzisiejszej sytuacji. Homoseksualizm (a tym bardziej praktyka performowania swojej płciowości i tożsamości genderowej przez bakla) kłóci się z oficjalnym stanowiskiem Kościoła katolickiego. Wątpliwe byłoby także utopijne myślenie, iż na Filipinach brak homofobicznych ekscesów - co dobrze pokazuje na przykład scena w Zsazsa Zaturnnah..., gdy główny bohater/główna bohaterka wspomina swoje dzieciństwo i znęcanie się ojca nad dzieckiem, które nie chce być „normalnym chłopcem”. Nie sposób wskazać też choćby jednego przykładu, kiedy to bakla pełniłaby na przykład ważną funkcję administracyjną czy polityczną (najczęściej pracuje jako fryzjer czy kosmetyczka, a o awansie społecznym można mówić wyłącznie w kontekście celebryckiej ka- riery w show-biznesie). Błędną oceną sytuacji byłaby jednak próba dowiedzenia, iż osoby nieheteroseksualne są wykluczone czy też znajdują się na marginesie społeczeństwa - choć przy tym jest to zależne przede wszystkim od miejsca ich zamieszkania (prowincja vs. metropolia).

To obszerne wprowadzenie było konieczne, by w pełni zrozumieć specyfikę tematu, który choć na tak odmienne sposoby - poruszają obaj reżyserzy. Maximo Oliveros rozkwita opowiada historię dwunastolatka, wychowywanego przez ojca i dwóch starszych braci - parających się drobnymi kradzieżami i obstawianiem nielegalnych zakładów. Bardzo szybko orientujemy się jednak, iż nie na tym polega specyfika owych relacji rodzinnych - najmłodszy z trzech synów, Maxi, jest bowiem bakla, dopiero co odkrywającą[5] swoją seksualność, i to jego przeżycia staną się główną osią prowadzonej narracji. Na przekór jednak wszelkim stereotypom - jest w pełni akceptowany przez ojca i braci. Maxi, jak się wydaje - z własnego wyboru - przejął przy tym rolę matki, opiekującej się rodziną: sprząta, gotuje (w tej roli nie ma sobie równych w całej dzielnicy) i wykonuje wszelkie codzienne obowiązki domowe. Pewnego dnia poznaje Victora Pereza, młodego policjanta, który ratuje go $\mathrm{z}$ opresji, gdy Maxi zostaje napadnięty w ciemnym zaułku. Victor -

[3] Oczywiście zdarza się, że bakla decyduje się np. na wszczepienie implantów kobiecych piersi, czasem podejmuje również decyzję o zmianie płci - obie praktyki są jednak marginalne. Wynika to nie tylko z sytuacji ekonomicznej większości populacji Filipin, lecz przede wszystkim $\mathrm{z}$ tradycji.

[4] J.N.C. Garcia, Performativity, the „Bakla” and the Orientalizing Gaze, w: Philippine Studies: have we gone beyond St. Louis?, Diliman, Quezon City 2008, s. 461.

[5] Warto w tym miejscu zaznaczyć, iż zastosowanie słowa bakla w języku polskim nastręcza wielu problemów, m.in. gdy decydujemy się na użycie rodzajów. W tagalog (jednym z języków urzędowych na Filipinach, najbardziej popularnym w rejonie Luzonu) nie istnieje bowiem podział na rodzaj męski czy żeński. 


\section{VARIA}

choć z początku dość naiwny w wyznawanych przez siebie zasadach, zupełnie nieprzystających do życia w manilskich slumsach - staje się dla dwunastolatka nieprześcignionym wzorem: jest nie tylko przystojny, lecz przede wszystkim na wskroś uczciwy, prawdomówny i pracowity. Sytuacja ulegnie diametralnej zmianie wraz z przybyciem nowego komendanta policji, proponującego młodemu Victorowi „szkolenie na prawdziwego glinę". Krzyżyk od ojca, który policjant otrzymał przed opuszczeniem prowincji, przestanie być amuletem, będzie już tylko niewiele znaczącą ozdobą na szyi. Nawet płynące wartkim strumieniem $\mathrm{z}$ jego ust przekleństwa czy coraz częstsze popadanie w nałogi okażą się niewiele znaczące $\mathrm{w}$ porównaniu $\mathrm{z}$ wplątaniem w zabójstwo, a co gorsza - z dość wątpliwymi i zbyt późno rodzącymi się wyrzutami sumienia. W mgnieniu oka dobre i złe charaktery zamieniają się miejscami - ci, którzy dotychczas pozostawali w konflikcie z prawem, wydają się przyjmować cechy bohatera pozytywnego; ci zaś, którzy mieli stać na straży owego prawa, przekraczają wszelkie dozwolone granice.

Maxi zaś, którego życie ulegnie tak znaczącej zmianie po stracie kolejnego członka rodziny, będzie zmuszony dokonać ostatecznego wyboru i podjąć decyzję, kto (jeśli w ogóle ktokolwiek) zasługuje na jego przebaczenie, oraz jaką ścieżką powinien on sam dalej podążać. Mimo że chłopiec ma dopiero dwanaście lat (a przy tym wciąż negocjuje swoją tożsamość seksualną i genderową oraz odkrywa zawiłe meandry ludzkiej seksualności), musi zmierzyć się z problemami, którym nie sprostałby niejeden dorosły.

Reżyser nie boi się prowadzić dość zawiłej gry z widzami - zakończenie filmu trudno bowiem opisać jako „otwarte”: przede wszystkim jest podwójne. Założenie przez Maxi szkolnego chłopięcego mundurka sugeruje pogodzenie się przez niego ze swoją, dopiero co "rozkwitającą" (by nawiązać do tytułu), męskością/kobiecością.

[6] C. Vergara, Ang Kagilagilalas na Pakikipagsapalaran ni Zsazsa Zaturnnah, collected edition, Makati City 2003.
Wtedy jednak musielibyśmy przyznać, iż poprzednio ukazane wydarzenia były wyłącznie dziecięcą igraszką, zabawą w „bycie baklą”, nie zaś spełnieniem marzeń i realizowaniem wewnętrznej potrzeby, by ją performować. Maxi zgodziłby się zatem na przyjęcie „zadanej” mu roli, biologicznej płci, przeczącej jego dotychczasowemu samoodczuwaniu. Pogodzenie się z tak zwaną normą, z narzuconymi przez część społeczeństwa czy religię zakazami, powinno być - biorąc pod uwagę ogólny wydźwięk fil$\mathrm{mu}$ - ukazane jako porażka. Tymczasem scena finałowa tego nie przedstawia. Nie można zapomnieć, iż Solito jest jednak mistrzem budowania fasady, której koherentność naruszają znakomicie wypreparowane drobiazgi. Delikatny francuski manicure i różowy odcień szkolnego plecaka nacinają jednoznaczność wymowy zakończenia. Być może zatem Maxi godzi się na podział na sferę publiczną i prywatną - będzie chłopcem w szkolnym mundurku od godziny ósmej do szesnastej, by móc korzystać z dobrodziejstw edukacji. W domu jednak, w przestrzeni, w której jego kobieca, „baklowa” natura wydaje się być w pełni akceptowana, nie będzie już niczego i nikogo odgrywać.

Zsazsa Zaturnnah: Ze Moveeh jest filmową adaptacją głośnego na Filipinach musicalu Zsazsa Zaturnnah, wystawionego w roku 2006 przez Tanghalang Pilipino - jedną z najważniejszych filipińskich grup teatralnych. Reżyser spektaklu Chris Millado we współpracy z Chrisem Martinezem i Vincentem de Jesus przenieśli na deski teatralne historię przedstawioną w komiksie Carlo Vergary Ang Kagila-gilalas na Pakikipagsapalaran ni Zsazsa Zaturnnah (Niesamowite przygody Zsazsa Zaturnnah)[6]. Musical ten nie tylko zdobył szereg nagród i na trwałe zapisał się w historii dwudziestopierwszowiecznego teatru filipińskiego, lecz także należy obecnie do najczęściej wystawianych przez Tanghalang Pilipino (dziewięćdziesiąt jeden wystawień w ciągu pięciu lat). Na fali tak zwanej Zsazsa-manii w tym samym roku powstał film w reżyserii Joela C. Lamangana. Różnice fabularne między wersją komiksową, teatralną 
i filmową są w istocie niewielkie. Zsazsa Zaturnnah: Ze Moveeh - podobnie jak u Vergary czy w adaptacji Tanghalang Pilipino - opowiada historię Ady, młodej bakla, która bez pamięci zakochuje się w obiekcie pożądania całego barangay [7] - Dodongu. Ada (skrót od męskiego imienia Adrian) jest pariolista - ma swój własny, całkiem dobrze prosperujący salon piękności. Wydaje się też, iż pomimo rozterek sercowych i druzgocącego zawodu miłosnego, wreszcie odnalazła „swoje miejsce na ziemi” - znakomicie pełni rolę opiekuna dla swojej siostrzenicy, ma wielu przyjaciół, którzy akceptują nawet to, iż nie do końca potrafi jeszcze określić własną tożsamość seksualną i genderową (co znakomicie ilustruje fakt, iż w porównaniu z Didi, inną zaprzyjaźnioną bakla, Ada wydaje się wciąż stać na granicy między „męskością” a „kobiecością"). Pewnego dnia przez dach jej domu wpada tajemniczy różowy kamień z napisem „Zaturnnah”. Po jego połknięciu Ada przemienia się w superbohaterkę - Zsazsę Zaturnnah. Nic nie dzieje się jednak przypadkowo - Ada jako Zsazsa w niedługim czasie będzie musiała uratować całą lokalną społeczność przed atakiem Amazonistas z planety Xxx. Nie trzeba dodawać, iż walka będzie długa i obfitująca w zaskakujące zwroty akcji - jednak w końcu Zsazsa wygra i, co zakłada większość musicali, nastąpi szczęśliwe zakończenie, także w kontekście jej perypetii sercowych.

Zsazsa Zaturnnah... to „święto” miłości i śmiechu, choć rządzą nim reguły przywodzące na myśl decorum porządkujące świat greckich tragedii. Brak tu bowiem dosłownych przedstawień śmierci (nawet Queen Femina zostanie stracona dopiero po opuszczeniu Ziemi, co nie zostaje ukazane ani w komiksie, ani w żadnej adaptacji), relacji seksualnych bez głębszych uczuć czy niepotrzebnej przemocy (walka jest tu zawsze walką heroiczną, toczoną w imię wyższych wartości, nieskalaną choćby jednym przekleństwem). Najbardziej widoczna jest jednak kampowa zabawa, pod której warstwą kryje się jednak dużo bardziej skomplikowany problem: Zsazsa Zaturnnah... to przecież także historia o dojrzewaniu i poszukiwaniu siebie.
Ada nie dostrzega - jak podkreśla Soledad S. Reyes - iż tak naprawdę dotychczas starał/a się rekompensować własne braki - wykonując zawód pariolista, pomagał/a przecież innym kobietom „stać się piękniejszymi”[8]. Zarówno w wersji komiksowej, jak i w obu adaptacjach nietrudno zauważyć, iż przed przemianą w superbohaterkę Ada jest permanentnie zagubiony/a. Nie wie, kim tak naprawdę jest próbuje odnaleźć się w roli mężczyzny, jednak zachowuje się, ubiera się i myśli o sobie jako o kobiecie. Przemiana w Zsazsę bynajmniej nie jest dla Ady prostym doświadczeniem - choć dzięki temu zyskuje szansę, by bohatersko uratować nie tylko przyjaciół, lecz w efekcie cały świat. Hiperkobiece (biorąc pod uwagę rozmiar biustu i kształt sylwetki) ciało staje się niestety pułapką, pustym, niewiele znaczącym „opakowaniem”, które pochłania jej prawdziwą tożsamość niczym czarna dziura. Szczęśliwe zakończenie nie wynika jedynie $\mathrm{z}$ faktu pokonania Amazonistas - o wiele istotniejsze jest to, iż Dodong zakochuje się w Adzie, nie w jej alter ego. W tej tylko relacji Ada może odnaleźć "prawdziwą siebie” - być kochaną jako bakla, być kochaną... jako kobieta z męskimi genitaliami, jako reprezentantka/reprezentant trzeciej płci.

Dzieła Solito i Lamangana różni przede wszystkim gatunek - Maximo Oliveros rozkwita to komediodramat, prowadzony w czasie rzeczywistym, który w wielu aspektach przypomina wręcz film dokumentalny, ukazujący najdrobniejsze szczegóły manilskiej codzienności. Solito nieobca jest praktyka posługiwania się słodko-gorzką ironią, co najlepiej pokazują choćby pierwsze minuty Maximo Oliveros... najazd kamery na rzekę wypełnioną po brzegi śmieciami, któremu towarzyszy powszechnie znana na Filipinach piosenka Yoyoya Villame My country, my Philippines.

[7] Barangay w tagalog oznacza zarówno dzielnicę, jak i miasteczko.

[8] Por. S.S. Reyes, From Darna to Zsazsa Zaturnnah: Desire and Fantasy. Essays on Literature and Popular Culture, Anvil Publishing, Pasig City 2009, s. 22-23. 


\section{VARIA}

Zsazsa Zaturnnah... z kolei to musical, łączący w sobie także elementy fantasy, utrzymany w zdecydowanej estetyce kampowej zabawy. Lamangan podąża tu oczywiście ścieżką wytyczoną już przez sam pierwowzór, a zatem komiks Vergary - Zaturnnah stanowi również połączenie dawnego filipińskiego mitu o Darnie oraz tak zwanej Wonder Woman, superbohaterki stworzonej w amerykańskiej serii DC Comics. Jednak przerysowanie, tak charakterystyczne dla komiksu, zostaje tu silnie wzmocnione kampową estetyką. Jak pisał Philip Core: „KAMP był więzieniem dla nielegalnej mniejszości, teraz jest świętem dla dorosłych świadomych swoich czynów" [9].

$\mathrm{W}$ obu przypadkach jedną $\mathrm{z}$ najważniejszych cech jest muzyczność - choć realizowana na tak różne sposoby. Piosenki skomponowane na potrzeby Zsazsa Zaturnnah... są czasem żywiołowe, czasem nostalgiczne, jednak zawsze doskonale dopasowane do nastroju konkretnej sceny. Utwory - czy sama ścieżka dźwiękowa w Maximo Oliveros... często wydają się działać na zasadzie kontrastu, stanowią bowiem nie tyle „dopowiedzenie”, ile raczej „podbicie” dla konkretnego ujęcia.

Melodramat, a właściwie melodramatyczność, stanowi tu główną oś gatunkową, warunkującą sposób prowadzenia narracji, rozwój wypadków czy ukazanie charakteru bohaterów. Nie jest to jednak melodramatyczność naiwna - ckliwa lub patetyczna. Rzecz jasna silnie oddziałuje na emocje i reakcje widzów, jednak zawsze pozostaje doprawiona szczyptą pikanterii i dobrego, choć często również prześmiewczego, humoru.

Reżyserzy proponują zatem zupełnie inne spojrzenie na współczesne społeczeństwo Filipin - bliskie codziennej rzeczywistości, nierozerwalnie złączone $\mathrm{z}$ „tu i teraz” oraz stosujące „filtr fantasy”, które wydaje się budować dystans

[9] „CAMP was a prison for an illegal minority, now it is a holiday for consenting adults", P. Core, From CAMP: Th Lie That Tells The Truth, w: Camp: Queer Aesthetics and the Performing Subject, red. F. Cleto, University of Michigan Press, Ann Arbor 1999, s. 8 o. i ironiczny cudzysłów. W przypadku Zsazsa Zaturnnah... trudno traktować monstrualną żabę czy atak zombie jako realne zagrożenie, jednak już w przypadku Maximo Oliveros... przemoc, wykorzystywanie i zabójstwa wydają się, w kontekście manilskiej codzienności, o wiele bardziej prawdopodobne. Mimo to oba filmy cechują "lekkość" i dystans w sposobie ukazania „ciemnej strony” Filipin - zarówno na „brudną Manilę", jak i biedną prowincję zostały nałożone „różowe okulary”.

\section{Résumé}

Solito w swoim reżyserskim debiucie stworzył obraz niezwykle ciekawy, jednak bez wątpienia silnie naznaczony konwencjonalnością. Lamangan zaś, dysponując pełnym zapleczem technicznym i finansowym oraz mając możliwość zaproszenia do współpracy znanych i cenionych sław filipińskiej sceny, nie bał się podjąć ryzyka kampowej przesady. To jednak pierwszy z nich był zapraszany i nagradzany na międzynarodowych festiwalach filmowych o Zsazsa Zaturnnah... nie sposób wręcz usłyszeć poza granicami Filipin.

Zarówno Maximo Oliveros rozkwita, jak i Zsazsa Zaturnnah: Ze Moveeh trudno zaliczyć do arcydzieł współczesnej kinematografii. Oba filmy w wielu aspektach wydają się niedopracowane, a ich estetyka - szczególnie w przypadku utworu Lamangana - wydaje się dość kontrowersyjna. O ich ważkości stanowi jednak odwaga mówienia o kwestii homoseksualizmu na Filipinach i niezaprzeczalna oryginalność w sposobie ukazania w tym kontekście problemów społecznych.

Oba filmy nie stwarzają naiwnej iluzji, iż filipińskie społeczeństwo w pełni akceptuje wszelkie nieheteronormatywne zachowania. Bycie bakla, reprezentowanie tej tak zwanej trzeciej płci, a przede wszystkim trudny, skomplikowany i czasochłonny proces budowania własnej tożsamości, wymykający się prostemu podziałowi hetero vs. homo, tak często musi zostać okupiony poczuciem odrzucenia, cierpieniem czy wręcz fizycznym bólem. Solito i Laman- 
gan potrafią jednak stworzyć obrazy, w których tragizm łączy się z komizmem, które fascynują wpisaną w nie zabawą, lekkością i uwodzą swym „różowym odcieniem”.

Maximo Oliveros rozkwita (Ang Pagdadalaga ni Maximo Oliveros), Filipiny 2005, UFO
Pictures, reż. Auraeus Solito, scen. Michiko Yamamoto, muz. Pepe Smith, Mike Villegas, zdjęcia Nap Jamir.

Zsazsa Zaturnnah: Ze Moveeh, Filipiny 2006, Regal Films Inc., reż. Joel C. Lamangan, scen. Dinno Erece, muz. Vincent de Jesus, zdjęcia Lyle Sacris.

\title{
Jerzy Wójcik - estetyka światła
}

\author{
KRZYSZTOF KOZŁOWSKI
}

Początki bywają niepozorne. Zacznijmy więc od zwięzłego dialogu otwierającego opublikowaną w Warszawie w roku 2006 książkę Jerzego Wójcika Labirynt światła:

- Nie masz żadnych zdjęć?

- Nie mam.

- Czy potrafisz robić zdjęcia?

- Nie. Nigdy nie robiłem zdjęć. Nie miałem aparatu... Mam rysunki...

I przedłożyłem komisji egzaminacyjnej kilka rysunków ołówkiem, jakieś akwarelki...

Był rok 1950. Zdawałem do Szkoły Filmowej. Komisja egzaminacyjna przyglądała się skromnym pracom. Na papierze narysowany był dom z płotem, rozbita kładka nad stawem...

Bohdziewicz, Wohl, Cękalski.

Rysunki przechodziły z rąk do rąk.

Ważyły się moje losy[1].

Pisząc te słowa, Wójcik miał już za sobą nie tylko realizacje filmów należących do ścisłego kanonu polskiego kina, lecz także wiele lat pracy jako wykładowca na Uniwersytecie Śląskim (1981-1982) i w Państwowej Wyższej Szkole Filmowej, Telewizyjnej i Teatralnej im. Leona Schillera w Łodzi (1982-2009). I mimo zażyłych kontaktów z licznymi filmowcami, nigdy nie udało mu się ustalić, co ostatecznie zadecydowało o przyjęciu go do szkoły filmowej. Tłumaczył to sobie faktem, że przyjechał z małego miasteczka i że trzeba było, aby w czasach panowania władzy komunistycznej, która na sztandarach miała wypisane hasła gloryfikujące „ludowośćc i proletariat, do szkoły dostał się ktoś, kto przyjechał z prowincji.

Rzeczywistość - jak wyjaśnia Wójcik - była okrutna. Zdawało kilkuset kandydatów. A na egzaminie wstępnym uratowała mnie prawdopodobnie wiedza z historii sztuki. [...] wiedziałem chyba o wiele więcej, niż należało. Egzaminatorzy zorientowali się, że opowiadam o sprawach, które są mi bliskie i współtworzą mój świat[2].

Dużo bardziej oczywiste dla przyszłego twórcy obrazów filmowych było to, komu winien zawdzięczać, iż po podziale blisko dwudziestoosobowej grupy studentów na „reżyserów” i „operatorów” mógł się wreszcie nauczyć robienia zdjęć, a w konsekwencji zostać profesorem szkoły filmowej.

Bez ich pomocy - doda - prawdopodobnie zostalbym wyrzucony ze szkoły. Są to [Antoni] Bohdziewicz, Krystyna Zwolińska i Jerzy Mierzejewski. Te osoby zwróciły na nas uwagę i potrafiły zachować się niezwykle taktownie, widząc nasze błędy. Byli to wykładowcy prawi w zawodzie i prawi w postępowaniu wobec studentów. To jest bardzo ważne, niezależnie od tego, że Bohdziewicz był bardzo dobrym pedagogiem, animatorem myśli związanej $\mathrm{z}$ reżyserią i kulturą filmową [3].

[1] J. Wójcik, Labirynt światła, Wydawnictwo Canonia, Warszawa 2006, s. 7 .

[2] Ibidem, s. 17.

[3] Ibidem, s. 18. 